\title{
Epidemiology and costs of cervical cancer screening and cervical dysplasia in Italy
}

Paolo Giorgi Rossi*1, Alessandro Ricciardi ${ }^{1}$, Catherine Cohet $^{2}$, Fabio Palazzo ${ }^{3}$, Giacomo Furnari ${ }^{1}$, Sabrina Valle ${ }^{1}$, Nathalie Largeron ${ }^{2}$ and Antonio Federici ${ }^{4}$

\author{
Address: ${ }^{1}$ Agency for Public Health, Lazio Region, Via di S. Constanza 53, 00198 Rome, Italy, ${ }^{2}$ Sanofi Pasteur MSD, 8 rue Jonas Salk, 69007 Lyon \\ France, ${ }^{3}$ National Research Council, Institute for Research on the Population and Social Policies, Via Nizza 128, 00198 Rome, Italy and ${ }^{4}$ Centre \\ for Disease Control, Ministry of Health, Via della Civiltà Romana 7, 00144 Rome, Italy \\ Email: Paolo Giorgi Rossi* - giorgirossi@asplazio.it; Alessandro Ricciardi - ricciardi@asplazio.it; Catherine Cohet - ccohet@spmsd.com; \\ Fabio Palazzo - f.palazzo@irpps.cnr.it; Giacomo Furnari - furnari@asplazio.it; Sabrina Valle - valle@asplazio.it; \\ Nathalie Largeron - nlargeron@spmsd.com; Antonio Federici - an.federici@sanita.it \\ * Corresponding author
}

Published: 25 February 2009

BMC Public Health 2009, 9:71 doi: I0.1 I86/I47|-2458-9-7|
Received: 14 October 2008

Accepted: 25 February 2009

This article is available from: http://www.biomedcentral.com/I47I-2458/9/7I

(c) 2009 Rossi et al; licensee BioMed Central Ltd.

This is an Open Access article distributed under the terms of the Creative Commons Attribution License (http://creativecommons.org/licenses/by/2.0), which permits unrestricted use, distribution, and reproduction in any medium, provided the original work is properly cited.

\begin{abstract}
Background: We estimated the number of women undergoing cervical cancer screening annually in Italy, the rates of cervical abnormalities detected, and the costs of screening and management of abnormalities.

Methods: The annual number of screened women was estimated from National Health Interview data. Data from the Italian Group for Cervical Cancer Screening were used to estimate the number of positive, negative and unsatisfactory Pap smears. The incidence of CIN (cervical intra-epithelial neoplasia) was estimated from the Emilia Romagna Cancer Registry. Patterns of follow-up and treatment costs were estimated using a typical disease management approach based on national guidelines and data from the Italian Group for Cervical Cancer Screening. Treatment unit costs were obtained from Italian National Health Service and Hospital Information System of the Lazio Region.
\end{abstract}

Results: An estimated 6.4 million women aged $25-69$ years undergo screening annually in Italy ( 1.2 million and 5.2 million through organized and opportunistic screening programs, respectively). Approximately $2.4 \%$ of tests have positive findings. There are approximately 21,000 cases of CINI and 7,000-17,000 cases of CIN2/3. Estimated costs to the healthcare service amount to $€ I 58.5$ million for screening and $€ 22.9$ million for the management of cervical abnormalities.

Conclusion: Although some cervical abnormalities might have been underestimated, the total annual cost of cervical cancer prevention in Italy is approximately $€ 181.5$ million, of which $87 \%$ is attributable to screening. 


\section{Background}

Cervical cancer is the second most common cancer in women worldwide and accounts for almost $10 \%$ of all cancer-related deaths. In Italy, it is estimated that each year 3,418 new cases and 1,186 deaths occur [1]. Infection with Human Papillomavirus (HPV) has been established as the necessary cause of cervical cancer [2,3]. As this cancer can be diagnosed at an early stage, screening programs using the Papanicolaou (Pap) smear test have reduced significantly the number of invasive cases, through the diagnosis and treatment of precancerous lesions (cervical intraepithelial neoplasia, [CIN]) $[4,5]$.

The Italian Ministry of Health establishes health-related objectives at national level, while implementation is the responsibility of regional governments. Some regions started implementing cervical cancer screening programs in the 1970s, while nationwide organized programs, rolled out on a regional basis, were recommended in 1996, based on the European Commission Guidelines on Quality Assurance in Cervical Cancer Screening [6]. By 1999, however, only 34\% of Italian women aged 25-64 years were included [7]. In 2004, the Italian Government ordered that each region should plan and implement cervical cancer screening programs [8], to be provided by Local Health Authorities. Such programs are still not fully implemented across the country, although opportunistic screening has increased. Two preventive cervical cancer vaccines (Gardasil ${ }^{\circledR}$ and Cervarix ${ }^{\circledR}$ ) are now registered in Italy. In March 2008, a mass vaccination campaign targeted at eleven-year-old girls was initiated, with some regions vaccinating a second cohort of girls (14 or 15 yearolds) and one region introducing a multi-cohort vaccination strategy, focused on four cohorts of girls aged 11, 14, 17 and 24 years.

In the absence of national data on the epidemiology of cervical cancer screening in Italy, the present study was undertaken to provide an estimation of the number of women undergoing screening annually, the annual incidence of cervical dysplasia, and direct costs associated with the management of women diagnosed with cervical dysplasia.

\section{Methods}

\section{Estimation of the annual number of Pap smears in Italy}

While organized screening programs publish the results of their activity periodically, information on opportunistic screening, i.e. Pap tests performed by public and private providers but not included in a screening program, is scarce. An estimation of the total number of women screened annually was obtained from a survey performed by the National Institute of Statistics (ISTAT) [9], which provides data on Pap test use and screening intervals by age and geographic area. The number of women screened by screening interval was calculated by multiplying the coverage (percentage) by the number of women aged 2569 years resident in Italy in 2005. To check the consistency of our estimate, we used two recently published studies to calculate the interval of screening (not shown) $[10,11]$. An alternative method, integrating data from the Italian Group for Cervical Cancer Screening (GISCi) for compliers and the ISTAT estimates for non-compliers, was used to obtain a lower bound in sensitivity analysis; this second hypothesis is based on the assumption that no women had a Pap test (neither from organized nor from opportunistic settings) in the three-year interval.

\section{Estimation of the annual number of abnormal Pap smears} Since 1997, the GISCi has been conducting surveys to assess screening programs, which until 2006 collected data on Pap tests and their results using the Bethesda System. The proportion of unsatisfactory samples and positive tests (including atypical squamous cells of undetermined significance [ASCUS], low-grade squamous intraepithelial lesions [LSIL], high-grade squamous intraepithelial lesions [HSIL] and suspected carcinoma) was obtained from the 2004 GISCi survey [11], and applied to the estimated annual number of Pap smears. To calculate the number of women referred for a repeat Pap smear, the proportion of unsatisfactory smears (6.1\%) was applied to the total annual number of Pap smears, and then multiplied by the compliance rate for repeated cytology (62.2\%), as observed in the GISCi survey [11].

\section{Management of abnormal cytology and treatment of pre- invasive lesions}

To establish the typical management of abnormal cytology and the management of cervical dysplasia, Italian and international guidelines for cervical cancer screening were reviewed. Published guidelines and protocols outlining details of patient management were identified through Medline Entrez-PubMed using the following search criteria: 'uterine cervical neoplasms', 'uterine cervical dysplasia', 'cervical intraepithelial neoplasia' AND 'screening'; the search was limited to 'practice guidelines'. In addition, a search of Embase and the Cochrane database was conducted using the search terms 'uterine cervix cancer' and 'uterine carcinoma in situ'.

The initial Medline search, concluded on 30 July 2006, gave 77 hits; a review of corresponding abstracts excluded 57 irrelevant, non-English or non-Italian articles. The Embase search did not add any new item. The reference sections of each identified article were checked for further guidelines (one additional item found). A screening of governmental agencies and Italian scientific societies identified 12 additional items. Agencies include the Italian National Health Agency (AgeNaS) and regional web- 
sites of Emilia Romagna, Piemonte, Veneto, Toscana, Lazio, Basilicata. The web database of the following international and national agencies was reviewed: IARC (International Agency for Research on Cancer), NHS (National Health Service) Cervical Screening Programme and NICE (National Institute for Clinical Excellence) UK, ANAES (Agence Nationale d'Accréditation et d'Évaluation en Santé) France, National Cervical Screening Programme New Zealand. The following Italian scientific societies were identified: GISCi (Italian Group for Cervical Cancer Screening), ONS (National Centre for Screening Monitoring), AIE (Italian Association of Epidemiology), SICi (Italian Society of Cytology), SICPCV (Italian Society of Cervical Pathology and Colposcopy) and SIAPEC (Italian Society of Pathology and Cytodiagnostics).

\section{Estimation of the annual number of CINI and CIN2/3 diagnoses}

In order to estimate the number of CIN1 lesions diagnosed each year, the CIN1 detection rate reported in the GISCi survey [11] was applied to the total number of Pap smears performed annually, although only 40 centres out of 95 organized cervical cancer screening programs participating in the GISCi survey registered data on CIN1 [12].

Two methods were used to estimate the number of CIN2/ 3 lesions. Method 1 was based on data from the Emilia Romagna Cancer Registry [13], the only Italian cancer registry providing reliable data on pre-invasive lesions. The detection rate was calculated by dividing the number of lesions by the estimated number of women screened in the same area and time period. This rate was then applied to the estimated total number of Pap smears performed annually in Italy. Method 2 applied the detection rate of CIN2/3 from the GISCi survey [11] to the total annual number of Pap smears. Currently, the number of CIN2, CIN3 and invasive carcinoma are reported in 75 out of 95 organized cervical cancer screening programs in Italy. The relative proportions of such lesions that were attributable to CIN2 and CIN3 were determined according to the results of the GISCi survey of second level screening for cervical cancer [12]. Both sources, the survey and the cancer registry, collect histological results according to the Richart classification for CIN.

\section{Costs associated with cervical screening and treatment of cervical dysplasia}

To calculate the total annual cost of cervical cancer screening from the healthcare perspective, unit costs for the relevant procedures were applied to the estimated numbers for total Pap tests and for women with each type of abnormal cervical cytology, based on the National Tariff Formularies [14] (Table 1). For women who had Pap tests performed within a screening program, there was an additional cost pertaining to each test invitation [[15]; ASP Lazio, unpublished data]. A cost for gynaecologic examination was added to the cost of Pap tests performed outside the screening program. Disruptive treatments for CIN (e.g. laser vaporization, cryotherapy, diathermocoagulation) were considered outpatient procedures.

It was assumed that excisional treatments for CIN (radiofrequency excision, cold-knife excision and laser conisation) were performed in hospital, either as day-hospital or inpatient procedures, and costs for these procedures were

Table I: Unit costs for invitation, diagnostic procedures and treatments.

\begin{tabular}{lr}
\hline Procedure & $\begin{array}{r}\text { Formulary code } \\
\text { (Lazio region) }\end{array}$ \\
\hline Invitation for screening & $\begin{array}{c}\text { Tariff }(\boldsymbol{\ell}) \\
\text { (not included in formularies) }\end{array}$ \\
Diagnostic & 3.33 \\
Pap test (conventional smear) & 91.38 .5 \\
HPV test & 91.37 .01 \\
Colposcopy & 70.21 \\
Endocervical biopsy & 67.11 \\
Histological evaluation of vaginal biopsy & 91.45 .5 \\
Gynecologic examination & 89.26 \\
Treatments & 81.60 \\
Disruptive & 10.74 \\
$\quad$ Laser vaporization & 24.79 \\
Cryotherapy & 14.10 \\
Excisional & 13.63 \\
$\quad$ Leep, cold blade and surgical conisation & 67.39 \\
$\quad$ Day hospital & 67.33 \\
$\quad$ Full hospitalization & None \\
\hline
\end{tabular}

Leep: loop electrical excision procedure 
obtained from the Lazio Hospital Discharge Registry (Table 1). All costs are reported in 2005 euros.

\section{Sensitivity analysis}

A sensitivity analysis was performed for five parameters:

1. For the total number of Pap tests, we used as lower bound of the estimate the result of a mixed method that includes the GISCi survey data and excludes overlaps between organised and opportunistic screening in the three-year period.

2. For the number of CIN2/3, we used the extrapolation from the GISCi survey as the higher bound of the estimate.

3. We varied the rate of referral to colposcopy from the value observed for the $25^{\text {th }}$ centile of the programmes distribution of the GISCi survey to the $75^{\text {th }}$ centile of this distribution.

4. We report the result of a hypothetical massive introduction of HPV testing for the triage of ASCUS, using the following assumptions: all ASCUS are referred to HPV test; the compliance to HPV test is $89 \%$ (as for colposcopy); the proportion of HPV positive among ASCUS is $24.2 \%$ [16]; the proportion of CIN $1 / 2 / 3$ consequent to ASCUS diagnosis among the total CIN $1 / 2 / 3$ in ASCUS + LSIL is $41 \%$ [16]; the biopsy rate among ASCUS HPV+ is arbitrarily set to $90 \%$; the HPV test cost is $81.60 €$ as national tariff and arbitrarily $15 €$ in the prevision of a strong price reduction.

5. Since the tariff of colposcopy is one of the lowest in industrialised countries, we report the total costs under the assumption that in opportunistic screening, colposcopy is always associated to a gynaecological visit.

6 . We report the total costs under the assumption of an inverted proportion of CIN1 treated (i.e. $63 \%$ instead of $37 \%)$.

7. We report the total costs under the extreme hypothesis of all conisations performed in outpatient settings. This does not apply to the conisations for recurrence.

\section{Results}

\section{Estimation of the annual number of Pap smears in Italy}

Our calculations suggest that a total of 6,423,924 women aged 25-69 years undergo screening on an annual basis in Italy (Table 2). According to ISTAT, there are approximately 16.5 million Italian women aged 25-64 years and therefore eligible for organized cervical screening. Given the recommended 3-year screening interval, approximately 5.5 million women (one-third of the target popu-
Table 2: Estimated annual number of Pap smears in women aged 25-69 years, Italy 2005.

\begin{tabular}{crr}
\hline & Number & $\%$ \\
\hline Total number of women & $6,423,924$ & 100.00 \\
Satisfactory Pap smears & $6,034,550$ & 93.9 \\
Unsatisfactory Pap smears & 389,376 & 6.1 \\
Repeat Pap smears & 242,194 & -- \\
Total number of Pap smears & $6,666,118$ & -- \\
\hline
\end{tabular}

lation) should be invited for cervical screening each year. However, screening programs only contact approximately 2.8 million women each year and 1.2 million of these women are actually screened [11]. These latter figures correspond to $27.5 \%$ and $11.8 \%$, respectively, of the female target population living in areas having active screening programs. Although the number of projected screened women includes some women beyond the recommended age for screening, it can be estimated that approximately 5.2 million women in Italy undergo opportunistic screening.

From a total of approximately 6.4 million women who undergo screening, it is estimated that about 390,000 have unsatisfactory results and, as a consequence, approximately 240,000 have a repeated test (Table 2). Overall, approximately 6 million women have a cytological result that permits assessment of their risk of cervical cancer.

\section{Estimation of the annual number of cytological abnormalities}

According to the GISCi survey 2004, 2.4\% of Pap tests were positive [11]. By applying this proportion to the estimated number of satisfactory tests, we estimate that 153,393 women have a positive result (Table 3 ). The most frequent finding is ASCUS, followed by LSIL.

\section{Management of women with abnormal cytology}

Twenty nine guidelines about screening and management of abnormal Pap tests were identified and reviewed. All current Italian guidelines recommend the TBS classification for cytology results (version 1991 followed by 2001). The management of LSIL, HSIL and suspected carcinoma is clearly defined: colposcopy and, if positive, biopsy. Conversely, ASCUS has three acceptable management options: colposcopy, repeat cytology at 6 months or HPV triage. On the basis of the GISCi data [11] and expert opinion, only direct referral to colposcopy was considered for the management of ASCUS. For HSIL, it was assumed that $90 \%$ of cases would undergo biopsy, but overall $49.6 \%$ of abnormal cases referred for colposcopy also underwent biopsy, as reported by GISCi [11]. We estimated that, of the 153,393 women with abnormal cytology, 134,054 would undergo colposcopy and 66,450 would have a biopsy. 
Table 3: Estimated cytology results for women aged 25-69 with a satisfactory Pap smear, Italy 2005.

\begin{tabular}{|c|c|c|c|}
\hline Cytology finding & $\mathbf{n}$ & \% Positive & \% Diagnosis \\
\hline Total number of satisfactory cytological diagnoses & $6,276,744$ & 100.0 & -- \\
\hline Negative & $6,123,349$ & 97.6 & -- \\
\hline Positive & 153,393 & 2.4 & 100.0 \\
\hline ASCUS & 68,161 & 1.09 & 44.4 \\
\hline LSIL & 44,539 & 0.71 & 29.0 \\
\hline HSIL & 11,976 & 0.19 & 7.8 \\
\hline Carcinoma & 678 & 0.01 & 0.4 \\
\hline Other ${ }^{1}$ & 28,039 & 0.45 & 18.3 \\
\hline
\end{tabular}

Includes women referred for colposcopy after two unsatisfactory Pap smears

There is no consensus guideline on the duration and frequency of follow-up of negative findings by colposcopy and biopsy. It was assumed that the typical follow-up for women with negative findings by colposcopy after LSIL or less severe cytological results was a Pap test after one year. The typical follow-up for negative colposcopy findings after HSIL or more severe cytological results was assumed to be two colposcopies with a repeated Pap test.

\section{Cost of cervical screening and management of abnormal Pap tests}

The total cost of cervical screening in Italy was estimated to be $€ 158.5$ million annually (Table 4). Most of these costs were associated with opportunistic screening. The costs of additional tests in women with an abnormal Pap smear were estimated to be approximately $€ 4.0$ million in the first year and $€ 5.2$ million including the costs of follow-up (Table 5). Most of these costs were attributable to women with ASCUS/LSIL. However, the unit cost per patient was higher for HSIL/carcinoma than for ASCUS/ LSIL (Table 5).

\section{Estimation of the annual number of CINI and CIN2/3 diagnosed in Italy}

It was estimated that 21,308 CIN1 lesions are diagnosed each year in Italian women. Estimates based on data from the Emilia Romagna Cancer Registry (Method 1) suggested that 6,982 CIN2/3 lesions are diagnosed annually: 3,218 cases of CIN2; 3,518 cases of CIN3; and 245 cases of adenocarcinoma in situ (AIS). These data excluded women aged less than 24 years, for whom there is no esti-

Table 4: Estimated annual costs of detection and management of cervical dysplasia (including follow-up), Italy 2005.

\begin{tabular}{lr}
\hline & Annual cost (€) \\
\hline Total screening costs & $158,541,733$ \\
Screening program & \\
$\quad$ Cost of invitations & $9,293,041$ \\
$\quad$ Cost of Pap smears & $13,104,094$ \\
Opportunistic screening & $130,140,608$ \\
Repeated Pap smears & $6,003,989$ \\
\hline
\end{tabular}

mate. The GISCi survey (Method 2) provided a substantially higher estimate for the total incidence of CIN $2 / 3$ of 16,571 cases $(7,638$ CIN2; 8,350 CIN3; 583 AIS) and 738 invasive cancers, resulting in a detection rate of 2.7/1000. The estimated incidence of AIS and invasive adenocarcinoma is lower than for squamous cell lesions. It was estimated that there would be 274 cases with recurrent CIN2 and 333 cases with recurrent CIN3 during a 2-year followup period.

\section{Management of cervical dysplasia (CIN)}

Sixteen guidelines about treatment of pre-invasive lesions were identified and reviewed. All current Italian guidelines recommend the Richart (CIN) classification for histology. A few Italian guidelines specifically refer to the treatment of CIN lesions. These include the Italian Society of Cervical Pathology and Colposcopy, the Italian Society for Gynaecology and Obstetrics (SIGO), the Society for Gynaecology and Obstetrics of Lombardy (SLOG) and those of the Emilia Romagna and Tuscany Regions. A review of these guidelines revealed three points where management practices may vary. First, it is recommended that CIN1 lesions should be followed up and treated only if persistent, or alternatively when the colposcopy is incomplete or the lesion is not completely visible. However, the GISCi survey found that the proportion of treated CIN1 lesions varies extremely between different centres [12].

Consequently, the overall percentage of treated CIN1 lesions from the GISCi survey (37\%) was used for all analyses. Secondly, guidelines recommend excision as the preferred treatment option for all grades of CIN, although the use of disruptive surgery is also allowed in some cases. Our estimates were based on the percentage of excisions and disruptive treatments observed in the GISCi survey for each CIN grade [12]. For CIN1, 63.0\% of cases had no immediate treatment (follow-up cytology and colposcopy at 6 months), $20.3 \%$ had disruptive treatment (29\% laser vaporization and $71 \%$ diathermocoagulation) and $16.7 \%$ had excisional treatments. For CIN2/3, 3.7\% and 96.3\% of cases had disruptive and excisional treatment, respec- 
Table 5: Estimated total and unit costs for diagnosis of abnormal Pap smears and treatment of CIN, Italy 2005.

\begin{tabular}{|c|c|c|c|c|}
\hline & \multicolumn{2}{|c|}{ First year } & \multicolumn{2}{|c|}{$\begin{array}{c}\text { Total cost } \\
\text { (First year and follow-up) }\end{array}$} \\
\hline & Total cost $(€)$ & Unit cost $(€)$ & Total cost $(€)$ & Unit cost $(€)$ \\
\hline Diagnosis & $3,986,007$ & 20.1 & $5,179,506$ & 33.8 \\
\hline ASCUS/LSIL & $2,780,336$ & 24.7 & $3,595,139$ & 31.9 \\
\hline HSIL/carcinoma & 499,034 & 41.7 & 602,402 & 50.3 \\
\hline Others & 706,637 & 24.6 & 981,965 & 34.2 \\
\hline $\mathrm{CIN}$ treatment & $16,381,037$ & 579.1 & $17,779,760$ & 628.5 \\
\hline CINII & $4,819,842$ & 226.2 & $5,580,319$ & 261.9 \\
\hline $\mathrm{CIN}^{2}{ }^{2}$ & $4,336,532$ & | 347.7 & $4,630,430$ & | 439.1 \\
\hline $\mathrm{CIN}^{2}$ & $7,224,664$ & 1919.4 & $7,569,011$ & 2010.9 \\
\hline Total & $20,367,044$ & & $22,959,267$ & \\
\hline
\end{tabular}

'Estimate based upon data from the GISCi 2004 survey [12]; 'Estimate based upon data from the Emilia Romagna Cancer Registry [13].

tively. The third point of discrepancy between guidelines is the duration and intensity of follow-up for CIN2/3 after treatment. It was assumed that all women would have had a repeat Pap test and colposcopy every 6 months for 2 years, as recommended in the guidelines from the Emilia Romagna Region. The estimated proportion of cases with recurrent CIN after treatment for CIN2/3 was based on findings reported in the study by Cecchini [17]. Any controversial points were discussed with an expert panel.

\section{Costs of cervical dysplasia treatment}

Using the lower estimate for the incidence rate of CIN2 and CIN 3, the total annual cost of treating CIN was $€ 16.4$ million, excluding any follow-up costs, and $€ 17.8$ million when follow-up costs were included. Treatment of CIN3 accounted for almost half of all costs (Table 5). The overall unit costs per patient were estimated to be $€ 579$ and $€ 628$, excluding and including costs of follow-up, respectively. The unit cost increased with disease severity.

If the higher estimates for incidence of CIN2 and CIN3 are used, the estimated costs of treatment (including followup) increase to $€ 11.8$ million and $€ 19.3$ million, respectively, and the overall cost of managing CIN could be as high as $€ 36.7$ million.

The combined cost of diagnosis and treatment of cervical lesions is $€ 22.9$ million, if the costs of follow-up are included (Table 5). When the costs of screening are included, the total annual cost of the cervical screening program amounts to $€ 181.5$ and $€ 200.5$ million, respectively, when the lower and the higher CIN2/3 incidence rates are considered.

\section{Sensitivity analysis}

The most influential parameters are the number of CIN2/ 3 , which increases the total cost by $6.4 \%$, and the setting for conisation, that can reduce the total costs up to $11.1 \%$ (Table 6).

\section{Discussion}

Our study suggests that costs associated with the detection and treatment of cervical dysplasia are substantial. Each year the Italian healthcare service is expected to spend $€ 181.5$ million ( $€ 200.5$ million if the higher incidence of CIN2+ lesions is taken into account) to screen approximately 6.4 million women aged 25-69 years, to manage more than 150,000 women with abnormal Pap smears, and to treat an estimated 21,000 women with CIN1 lesions and 7,000-17,000 women with CIN2/3 lesions. Although the majority of these costs are directly related to cervical screening, only a small proportion is attributable to organized screening programs, with opportunistic testing accounting for the greatest share of costs. In contrast, our estimates suggest that only $11 \%$ of the total healthcare costs are associated with the management of CIN lesions; this percentage increases to $18 \%$ if the higher CIN2/3 incidence rate is applied.

Interestingly, although approximately 6.4 million women have a Pap test each year, which should cover the target population for organized screening, there are still $30 \%$ of women who had no Pap test in the last three years. Only 1.2 million women are screened within organised programs, but approximately 5.2 million are screened opportunistically. This suggests that some women are screened more frequently than the recommended 3-year interval, while others are screened despite being older than the recommended age, whereas some women may never be screened. This is consistent with analyses from the ISTAT data, showing that up to $50 \%$ of women in Southern Italy and the Italian islands have never been screened, compared with approximately $25 \%$ of women in Northern and Central Italy [18]. 
Table 6: Univariate sensitivity analysis of screening, abnormal findings management and treatment costs (€), Italy 2006.

\begin{tabular}{|c|c|c|c|}
\hline & Screening & Abnormal findings and treatment & $\begin{array}{r}\text { Total costs of cervical cancer } \\
\text { prevention }\end{array}$ \\
\hline Baseline values for all the parameters & $158,288,703$ & $22,959,267$ & $181,247,970$ \\
\hline \multicolumn{4}{|l|}{ No. of screened women yearly } \\
\hline \multicolumn{4}{|l|}{$\begin{array}{l}\text { baseline: extrapolation from ISTAT } \\
(N=6,423,924)\end{array}$} \\
\hline $\begin{array}{l}\text { lower case: similar, but excluding overlap } \\
\text { between opportunistic and organised } \\
\text { screening }(N=6,270,130)\end{array}$ & $154,332,393$ & $22,825,230$ & $177,157,624$ \\
\hline \multicolumn{4}{|l|}{ No. of $\mathrm{CIN} 2 / 3$ found } \\
\hline \multicolumn{4}{|l|}{$\begin{array}{l}\text { baseline: estimate from Emilia Romagna } \\
\text { cancer registry }(N=6,982)\end{array}$} \\
\hline $\begin{array}{l}\text { higher case: extrapolation from GISCi } \\
\text { survey }(N=16,57 \mathrm{I})\end{array}$ & $158,288,703$ & $34,532,811$ & $192,821,515$ \\
\hline \multicolumn{4}{|l|}{ Referral rate } \\
\hline \multicolumn{4}{|l|}{$\begin{array}{l}\text { baseline: extrapolation from GISCi survey } \\
(2.5 \%)\end{array}$} \\
\hline $\begin{array}{l}\text { lower case: } 25 \text { th centile of the GISCi } \\
\text { survey distribution (1.5\%) }\end{array}$ & $158,288,703$ & $20,920,849$ & $179,209,552$ \\
\hline $\begin{array}{l}\text { higher case: } 75 \text { th centile of the GISCi } \\
\text { survey distribution (3\%) }\end{array}$ & $158,288,703$ & $24,235,135$ & $182,523,838$ \\
\hline \multicolumn{4}{|l|}{ ASCUS management } \\
\hline \multicolumn{4}{|l|}{ baseline: no triage with HPV test } \\
\hline $\begin{array}{l}\text { triage with HPV test (cost } 81.60 € \\
\text { according to national tariff) }\end{array}$ & $158,288,703$ & $26,101,216$ & $184,389,919$ \\
\hline triage with HPV test (cost $15.00 €)$ & $158,288,703$ & $22,197,251$ & $180,485,954$ \\
\hline \multicolumn{4}{|l|}{ Colposcopy setting } \\
\hline \multicolumn{4}{|l|}{ baseline: no gynaecological visit } \\
\hline $\begin{array}{l}\text { upper case: gynaecological visit for } \\
\text { colposcopies performed in opportunistic } \\
\text { screening }\end{array}$ & $158,288,703$ & $25,199,706$ & $183,488,409$ \\
\hline \multicolumn{4}{|l|}{ CINI treatment } \\
\hline upper case: $63 \%$ of CINI treated & $158,288,703$ & $26,231,936$ & $184,510,639$ \\
\hline \multicolumn{4}{|l|}{ Conisation setting } \\
\hline \multicolumn{4}{|l|}{$\begin{array}{l}\text { baseline: inpatient } \\
\text { ( } 36 \% \text { day hospital and } 64 \% \text { full } \\
\text { hospitalization) }\end{array}$} \\
\hline lower case: outpatient & $158,288,703$ & $8,084,711$ & $|66,373,4| 4$ \\
\hline
\end{tabular}

This study has several limitations. Firstly, extrapolation of GISCi data to the whole Italian female population may result in an overestimation of the number of women screened and in an underestimation of CIN management. Secondly, although the GISCi survey represents the only available data relating to screening programs from different Italian regions, this data collection system neither includes opportunistic screening carried out in the private setting, nor takes into account data from each Italian region. Furthermore, some Italian regions do not yet have formalized screening programs, and data included in the GISCi survey $2004[11,12]$ are, therefore, collected exclusively in regions with well-established programs. Thirdly, the absence of any national data on opportunistic screening, which accounts for the majority of screening in Italy, also limits estimates of the epidemiology of cervical dysplasia. Lastly, we could not estimate the number of cases of CIN2/3+ for women younger than 24 years of age and older than 70 years. Although a small proportion of CIN2/3+ occurs in women under 24 years of age, such lesions are very likely to regress [19] and, according to guidelines, should not be diagnosed [8]. Conversely, very few women over 70 years of age have Pap smears. Our calculations assume that in situ lesions detected in women older than 69 years, as reported by the Emilia Romagna Cancer Registry, can be attributed to Pap smears performed in women aged 65-69 years.

The two methods used to estimate the annual number of CIN2/3 lesions produced markedly different values. Method 1, based on data from the Emilia Romagna Cancer Registry, suggested that there are about 7,000 cases of CIN2/3 diagnosed. However, data drawn from a single registry cannot have $100 \%$ sensitivity to accurately project the incidence of these lesions nationwide, especially as this data collection is relatively new and does not have 
well-established quality indicators, such as for invasive cancer. The value derived using Method 1 can, therefore, be used as a lower limit of the CIN2/3 range. Method 2, which used data from the GISCi survey, suggested that there are more than 17,000 cases of CIN2+ diagnosed each year. This number might overestimate the incidence rate, as the detection rate observed in organized screening programs using a 3-year interval is probably higher than the detection rate of opportunistic screening, often based on a 1-year interval. This estimate can, therefore, be used as the upper limit of the CIN2/3 range. In our sensitivity analysis, this parameter appeared to be one of the most influential, resulting in the highest cost estimate $(+6.3 \%)$.

With reference to the annual expected number of CIN 1 , it should be noted that only $42.1 \%$ (40 out of 95 ) of centres participating in the GISCi survey systematically provide data. Although these lesions do not generally require treatment, it is commonly agreed in clinical practice, particularly in opportunistic screening, that deviations from best practice are frequent and over-treatment is often performed. Consequently, the impact of CIN1 treatment on costs might have been underestimated.

In the cost calculations, it was assumed that all women with ASCUS would be referred directly for colposcopy, although this is not entirely consistent with current guidelines or clinical practice. However, the introduction of HPV triage does not change substantially the total costs, as shown by the sensitivity analysis. Nevertheless, estimation of the costs of additional diagnostic procedures for LSIL and HSIL and for treatment of CIN was based on practices reported in the GISCi survey, so may be considered representative of current practice in Italy.

The shift of treatment procedures to a more appropriate setting of care, in particular conisation from inpatient to outpatient is currently the most suitable way to reduce total costs of disease. Nevertheless, a change in the setting of surgery from day hospital to outpatient has a strong impact if tariffs are used to measure costs, but this is an overestimation of the real impact on the real costs sustained by the Health Service.

Although it is not possible to make direct cost comparisons between different healthcare systems, it is interesting to note that the costs of cervical screening in Italy are comparable with those for England, where approximately 4 million women are screened each year at a cost of $€ 157$ million (approximately $€ 200$ million), including the cost of treating abnormalities [20]. However, the estimated cost per case associated with CIN1 treatment in the present study was lower in comparison with the mean cost reported in England and Wales (€419; approximately $€ 532)$, whereas the estimated unit costs for CIN2 and
CIN3 were considerably higher than the mean costs (€572 [approximately $€ 726$ ] and $€ 606$ [approximately €770], respectively) [21].

As the focus of this study was the economic burden of cervical dysplasia, our calculations did not take into account societal costs, such as work loss due to screening or for CIN treatment. We also did not capture the psychological burden of receiving a positive Pap smear result.

Until recently, regular screening was the only tool to prevent cervical cancer. The development of HPV vaccines has provided a new opportunity to reduce the incidence of cervical dysplasia [22-24] and studies have shown that a combination of both vaccination and screening is a costeffective solution to reduce morbidity and mortality caused by cervical cancer [25-28].

\section{Conclusion}

This is the first study to assess the epidemiology of cervical cancer screening and cervical dysplasia, as well as the associated healthcare costs, for Italy as a whole. Each year, the Italian healthcare service system makes a substantial investment of $€ 158.5$ million for the provision of screening services and $€ 22.9$ million for the follow-up and treatment of cervical abnormalities.

Higher adhesion to guidelines and protocols would produce substantial savings. Although the number of Pap tests performed each year would be sufficient to cover the whole target population, $30 \%$ of women are still not screened.

The economic burden of disease associated with cervical dysplasia identified in this study will assist health authorities with both the planning and allocation of funding for an effective cervical cancer prevention strategy.

\section{Abbreviations}

ASCUS: atypical squamous cells of undetermined significance; CIN: cervical intraepithelial neoplasia; GISCi: Italian Group for Cervical Cancer Screening (Gruppo Italiano Screening del Cervicocarcinoma); HPV: human Papillomavirus; HSIL: high-grade squamous intraepithelial lesions; ISTAT: National Institute of Statistics (Istituto nazionale di statistica); LSIL: low-grade squamous intraepithelial lesions.

\section{Competing interests}

The Agency for Public Health (ASP Lazio) received an unrestricted grant from Sanofi Pasteur MSD to conduct the present study. Results of this study were analysed independently from Sanofi Pasteur MSD. CC and NL are employed by Sanofi Pasteur MSD. AR, FB, GF and SV have no competing interests. PGR received travel reimburse- 
ment to present the results of this study in two conferences. AF received travel grants for conference attendance.

\section{Authors' contributions}

PGR designed the study protocol, conducted the overall epidemiological analysis and wrote the study report. FP conducted the economic analysis and contributed to the report. AR collected the unit costs and contributed to the economic analysis. CC and NL contributed to the epidemiological and economic analyses and the study report. GF and SV conducted the literature reviews and helped collect the epidemiological data. AF contributed to the study design. All authors have approved the final version of the manuscript.

\section{Acknowledgements}

Expert panel: Professors Sergio Pecorelli, Aldo Vecchione, Maria Rosaria Giovagnoli and Doctor Patrizio Raggi for ad hoc advice. Laurence SerradellVallejo (Sanofi Pasteur MSD, Lyon, France) for overall coordination of the study. Alessandro Capone (Sanofi Pasteur MSD, Rome, Italy) for review of the data and study report. Vijan lyer and Alison Taylor (Communigen Ltd., Oxford, UK) and Hannah Lewis (MedEd Ltd., Shepperton, UK) for assistance with writing the manuscript.

\section{References}

I. Ferlay J, Bray F, Pisani P, Parkin DM: GLOBOCAN 2002: Cancer Incidence, Mortality and Prevalence Worldwide. In IARC CancerBase No. 5. version 2.0 IARC Press, Lyon; 2004.

2. Walboomers JM, Jacobs MV, Manos MM, Bosch FX, Kummer JA, Shah KV, Snijders PJ, Peto J, Meijer CJ, Muñoz N: Human papillomavirus is a necessary cause of invasive cervical cancer worldwide. J Pathol 1999, 189:12-19.

3. Muñoz N: Human papillomavirus and cancer: The epidemiological evidence. J Clin Virol 2000, 19:1-5.

4. Quinn M, Babb P, Jones J, Allen E, on behalf of the United Kingdom Association of Cancer Registries: Effect of screening on incidence of and mortality from cancer or cervix in England: Evaluation based on routinely collected statistics. BMJ 1999, 3 1 8:904-8.

5. Minelli L, Stracci F, Prandini S, Fusco Moffa I, La Rosa F: Gynaecological cancers in Umbria (Italy): Trends in incidence, mortality and survival, 1978-1998. Eur J Obstet Gynecol Reprod Biol 2004, I I 5:59-65.

6. Coleman D, Day N, Douglas G, Farmery E, Lynge E, Philip J, Segnan $\mathrm{N}$ : European guidelines for quality assurance in cervical cancer screening. Eur J Cancer I993, 29A(Suppl 4):SI-38.

7. Segnan N, Ronco G, Ciatto S: Cervical cancer screening in Italy. Eur J Cancer 2000, 36:2235-9.

8. Ministero della Sanità: Linee Guida elaborate dalla Commissione Oncologica Nazionale per il triennio 1994-relative all'azione programmata "prevenzione e Cura delle malattie oncologiche", concernenti l'organizzazione della prevenzione e dell'assistenza in oncologia. Gazzetta Ufficiale N. 127. //6/ 19961996 [http://www.guritel.it/free-sum/ARTI//996/06/01/somma rio.html].

9. Istituto Nazionale di Statistica [http://www.istat.it]

10. Giorgi Rossi P, Esposito G, Brezzi S, Brachini A, Raggi P, Federici A: Estimate of Pap-test coverage in an area with an organised screening program: Challenges for survey methods. $B M C$ Health Serv Res 2006, 6:36.

II. R Ronco G, Giubilato P, Naldoni C, Zorzi M, Anghinoni E, Scalisi A, Dalla Palma P, Zanier L, Federici A, Angeloni C, Prandini S, Maglietta R, Mancini E, Pizzuti R, lossa A, Segnan N, Zappa M: Activity level and process indicators of organised programmes for cervical cancer screening in Italy. Epidemiol Prev 2006, 30(I Suppl 3):27-40.
12. Volante R, Ronco G: National survey of the quality of second level screening for cervical cancer. Epidemiol Prev 2006, 30(Suppl 3):49-55.

13. Emilia Romagna Cancer Registry [http://www.rtm.unimo.it]

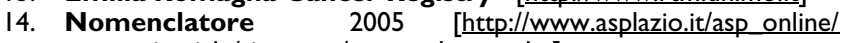
att territoriale/sias new/nomenclatore.php].

15. Zappa M, Cecchini S, Ciatto S, lossa A, Falini P, Mancini M, Paci E: Measurement of the cost of screening for cervical cancer in the district of Florence, Italy. Tumori 1998, 84:63I-5.

16. Ronco G, Segnan N, Giorgi-Rossi P, Zappa M, Casadei GP, Carozzi F, Dalla Palma P, Del Mistro A, Folicaldi S, Gillio-Tos A, Nardo G, Naldoni C, Schincaglia P, Zorzi M, Confortini M, Cuzick J, New Technologies for Cervical Cancer Working Group: Human papillomavirus testing and liquid-based cytology: results at recruitment from the new technologies for cervical cancer randomized controlled trial. J Natl Cancer Inst 2006, 98(I I):765-74.

17. Cecchini S, Carozzi F, Confortini M, Zappa M, Ciatto S: Persistent human papillomavirus infection as an indicator of risk of recurrence of high-grade cervical intraepithelial neoplasia treated by the loop electrosurgical excision procedure. Tumori 2004, 90:225-8.

18. Mancini E, Segnan N, Ronco G: I determinanti del ricorso allo screening dei tumori femminili. Statistical and political information for the promotion of health. Actions of the Rome convention, ISTAT 2002.

19. Adelstein AM, Husain OAN, Spriggs Al: Cancer of the cervix and screening. BMJ 198I, 282:564.

20. NHS Cervical Screening Programme [http://www.cancer screening.nhs.uk/cervical/index.html]

21. Martin-Hirsch P, Rash B, Martin A, Standaert B: Management of women with abnormal cervical cytology: treatment patterns and associated costs in England and Wales. BJOG 2007, I 1 4:408-15.

22. Garland SM, Hernandez-Avila M, Wheeler CM, Perez G, Harper DM, Leodolter S, Tang GW, Ferris DG, Steben M, Bryan J, Taddeo FJ, Railkar R, Esser MT, Sings HL, Nelson M, Boslego J, Sattler C, Barr E, Koutsky LA, Females United to Unilaterally Reduce Endo/Ectocervical Disease (FUTURE) I Investigators: Quadrivalent vaccine against human papillomavirus to prevent anogenital diseases. New Engl J Med 2007, 356: 1928-43.

23. Ault KA, FUTURE II Study Group: Effect of prophylactic human papillomavirus $L I$ virus-like particle vaccine on risk of cervical intraepithelial neoplasia grade 2 , grade 3 , and adenocarcinoma in situ: A combined analysis of four clinical trials. Lancet 2007, 369: 186I-8.

24. Paavonen J, Jenkins D, Bosch FX, Naud P, Salmerón J, Wheeler CM, Chow SN, Apter DL, Kitchener HC, Castellsague X, de Carvalho NS, Skinner SR, Harper DM, Hedrick JA, Jaisamrarn U, Limson GA, Dionne M, Quint W, Spiessens B, Peeters P, Struyf F, Wieting SL, Lehtinen MO, Dubin G, HPV PATRICIA study group: Efficacy of a prophylactic adjuvanted bivalent LI virus-like-particle vaccine against infection with human papillomavirus types 16 and 18 in young women: an interim analysis of a phase III double-blind, randomised controlled trial. Lancet 2007, 369:2161-70.

25. Dasbach EJ, Insinga RP, Elbasha EH: The epidemiological and economic impact of a quadrivalent human papillomavirus vaccine (6/I I//6/18) in the UK. BJOG 2008, I I5(8):947-56.

26. Kim Jj, Goldie SJ: Health and economic implications of HPV vaccination in the United States. N Engl J Med 2008, 359(8):82I-32.

27. Jit M, Choi YH, Edmunds WJ: Economic evaluation of human papillomavirus vaccination in the United Kingdom. BMJ 2008, 337:a769. doi: $10.1136 / \mathrm{bmj} . \mathrm{a} 769$

28. Goldhaber-Fiebert JD, Stout NK, Salomon JA, Kuntz KM, Goldie SJ: Cost-effectiveness of cervical cancer screening with human papillomavirus DNA testing and HPV-16,18 vaccination. J Natl Cancer Inst 2008, 100:308-20.

\section{Pre-publication history}

The pre-publication history for this paper can be accessed here:

http://www.biomedcentral.com/1471-2458/9/71/prepub 